\title{
What Should I Spend On Marketing?
}

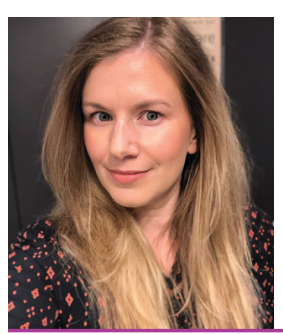

Zoey Duncan

Zoey Duncan is a Content Strategist at Marketing4ECPs where she crafts custom content imbued with each client's particular voice. Zoey has been writing and editing for more than a decade as a journalist, author, and ghostwriter. When she's away from the keyboard, Zoey can be found sewing her own clothes or riding her bike around Calgary. You can find out more about Zoey and Marketing4ECPs here at www.marketing4ecps.com. investment. You're putting money into your business in order to grow it, gain patients, and increase profits.

If you've invested in marketing before and didn't get the results you were hoping for, it could be that you weren't spending enough to make an impact, tracking was difficult or it was not set up properly (example: targeting for an digital ad campaign). Determining the ideal starting figure for your marketing investment will come down to what growth you want to see and importantly, where you're at right now.

\section{KNOW YOUR BIG NUMBERS}

Maybe you've previously been told to spend $5 \%$ of last year's sales or $7 \%$ of future sales. These figures might work in certain industries and situations but not all. A better starting point when it comes to an eye care practice is looking at your trailing 12 month revenue.

\section{Look Where You've Been to See Where You Can Go}

Let's say it's fair to assume that if you spend the same amount on marketing in the next 12 months as you did in the previous 12, you'll get the same results. That means you can look backward to create your marketing budget.

If your practice made $\$ 1$ million in the last 12 months and you spent $\$ 25,000$ on marketing to achieve that, that's a $2.5 \%$ marketing cost.

If you've decided you want to grow your earnings by $20 \%$ in the next year to bring in $\$ 1.2$ million, you'll need to increase your marketing spend. A good guide is to invest $10 \%$ of your desired growth. In this example, we want to see $\$ 200,000$ of growth, add $\$ 20,000$ to the marketing budget for a total of $\$ 45,000$.

\section{KNOW YOUR SMALL NUMBERS}

But how will you divide up that marketing investment? You (or your marketing company) absolutely need to know the smaller key numbers behind each patient. This is what allows you to spend your marketing dollars effectively, whether that's building a website that converts visitors into patients or running digital advertising campaigns.

\section{Per-Patient Revenue}

Do you know how much a new patient is worth? This is a key figure to track in-clinic because it will determine a range for how much it's worth to spend on acquiring each new patient. We find the average patient revenue is typically between $\$ 300$ and $\$ 500$.

\section{Patient Acquisition Cost}

When you know what each patient is worth, you can determine a cost to acquire more similar patients. Using our previous example, if your average patient brings in $\$ 500$, you might be willing to invest $15 \%$ of that revenue, or $\$ 75$, to acquire a new patient. A $\$ 75$ investment to earn $\$ 500$ looks pretty good on most spreadsheets. 


\section{Your Lead-to-Patient Rate}

But you know that you can't expect every person who visits your website or who sees one of your ads to become a patient. You need to know how many of your leads become patients. This is your lead-to-patient rate.

If this isn't something you currently track, you can estimate that for an eye care practice, about 30-50\% of your qualified leads will convert to patients. If your practice has a lead-to-patient rate of 50\%, you'll need to attract an average of two leads to get one patient.

Using our $\$ 75$ per patient investment, that means spending $\$ 37.50$ for each new lead.

\section{Give the Money Time to Work}

Your cost per lead of $\$ 37.50$ gives you a starting point for your marketing. The great thing about digital advertising is that you tweak things on the fly, for example if you learn that you're in a less-competitive market, you can spend less per lead-and vice-versa.

Wherever you choose to put those marketing dollars, just be sure you give them enough time to show results. At minimum, you want to wait one or two quarters to see an effect on your practice.

Now, spreadsheets aren't what compelled you to devote your life to eye care. But by getting a handle on both the big numbers and the small ones, you'll find you have the resources to grow your practice to new heights.

Last thoughts, digital advertising done right should make you money, not cost you money. It almost always pays for itself. 